\title{
Ein guter Fang!
}

- In unserer Geburtstagsausgabe im Mai lag der ergopraxis ein Fragebogen bei. Wir wollten von Ihnen wissen, ob wir mit unserer Themenauswahl richtig liegen. Oder ob wir im Trüben fischen und Ihnen möglicherweise Informationen fehlen. An dieser Stelle bedanken wir uns herzlich bei allen, die an der großen Leserumfrage teilgenommen haben!

_ 91,9 Prozent der Befragten beurteilten die ergopraxis positiv: 23,6 Prozent mit sehr gut und 68,2 Prozent mit gut. Offensichtlich haben wir mit unserer Themenvielfalt, dem hohen Praxisbezug und der starken Berufsnähe bei Ihnen ins Schwarze getroffen. Das motiviert uns ganz besonders! Denn Simone Gritsch, Maria Czyganowski und ich sind ebenfalls Ergos. Und wir möchten, dass sich das auch in unseren Heften widerspiegelt!

_ Für 96 Prozent der befragten Leser war „Profession E Perspektiven“ die wichtigste Rubrik, gefolgt von der Rubrik „Ergotherapie“ mit 68 Prozent. Besonders erfreulich fanden wir, dass Sie mit uns im mittlerweile großen ergotherapeutischen Studienozean nach Wirksamkeitsperlen tauchen gehen: 85 Prozent der befragten Leser empfanden das Niveau der wissenschaftlichen Themen als genau richtig. Mit Ihren Antworten haben Sie uns zahlreiche gute Anregungen und Ideen gegeben, die wir in unseren nächsten Ausgaben gerne aufgreifen werden.

_ Am Ende dieses Heftes haben wir wie in jeder Doppelausgabe wieder ein Rätsel für Sie. Ziehen Sie diesmal dicke Fische aus dem Wasser und angeln Sie sich mit dem richtigen Lösungswort einen unserer tollen Preise. Ich wünsche Ihnen viel Glück und einen guten Fang!

Sommerliche Grüße

von Ihrer

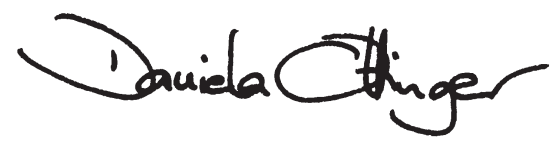

PS: Diesem Heft liegt erstmals unser ergopraxis.Refresher bei. Begeben Sie sich auf zu neuen Ufern und probieren Sie diese etwas andere Art aus, sich fortzubilden.

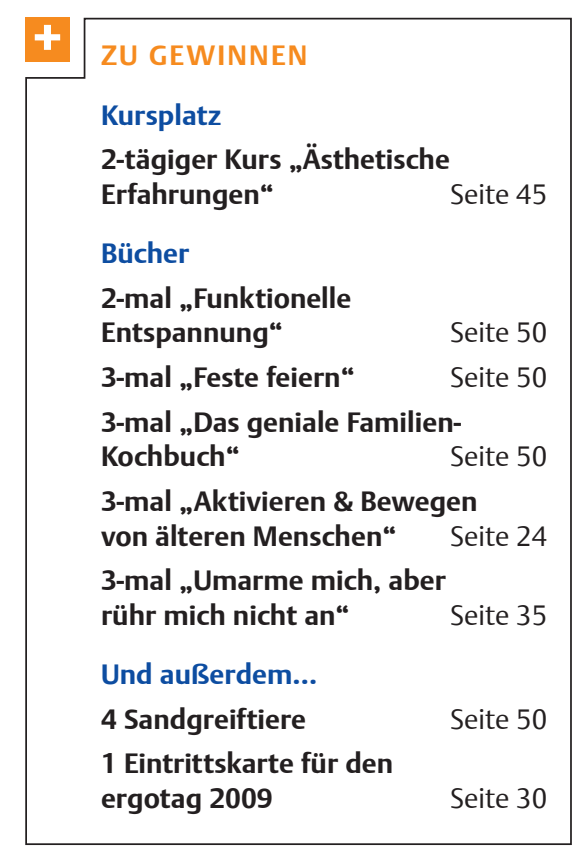

